\title{
Brown adipose tissue oxidative metabolism contributes to energy expenditure during acute cold exposure in humans
}

Véronique Ouellet, ${ }^{1}$ Sébastien M. Labbé, ${ }^{2}$ Denis P. Blondin, ${ }^{3}$ Serge Phoenix, ${ }^{2,4}$ Brigitte Guérin, ${ }^{4}$ François Haman, ${ }^{3}$ Eric E. Turcotte,${ }^{4}$ Denis Richard, ${ }^{1}$ and André C. Carpentier ${ }^{2}$

${ }^{1}$ Centre de recherche de l'Institut universitaire de cardiologie et de pneumologie de Québec, Université Laval, Quebec City, Quebec, Canada.

2Department of Medicine, Centre de recherche clinique Etienne-Le Bel, Université de Sherbrooke, Sherbrooke, Quebec, Canada.

${ }^{3}$ Unité de recherche sur la nutrition et le métabolisme, Montfort Hospital, University of Ottawa, Ottawa, Ontario, Canada.

${ }^{4}$ Department of Nuclear Medicine and Radiobiology, Université de Sherbrooke, Sherbrooke, Quebec, Canada.

\begin{abstract}
Brown adipose tissue (BAT) is vital for proper thermogenesis during cold exposure in rodents, but until recently its presence in adult humans and its contribution to human metabolism were thought to be minimal or insignificant. Recent studies using PET with ${ }^{18} \mathrm{~F}$-fluorodeoxyglucose $\left({ }^{18} \mathrm{FDG}\right)$ have shown the presence of BAT in adult humans. However, whether BAT contributes to cold-induced nonshivering thermogenesis in humans has not been proven. Using PET with ${ }^{11} \mathrm{C}$-acetate, ${ }^{18} \mathrm{FDG}$, and ${ }^{18} \mathrm{~F}$-fluoro-thiaheptadecanoic acid ( ${ }^{18}$ FTHA), a fatty acid tracer, we have quantified BAT oxidative metabolism and glucose and nonesterified fatty acid (NEFA) turnover in 6 healthy men under controlled cold exposure conditions. All subjects displayed substantial NEFA and glucose uptake upon cold exposure. Furthermore, we demonstrated cold-induced activation of oxidative metabolism in BAT, but not in adjoining skeletal muscles and subcutaneous adipose tissue. This activation was associated with an increase in total energy expenditure. We found an inverse relationship between BAT activity and shivering. We also observed an increase in BAT radio density upon cold exposure, indicating reduced BAT triglyceride content. In sum, our study provides evidence that BAT acts as a nonshivering thermogenesis effector in humans.
\end{abstract}

\section{Introduction}

Brown adipose tissue (BAT) is a specialized tissue whose function is to produce heat $(1,2)$. Its thermogenic capacity is such that it allows mammals to live below thermoneutral conditions without having to rely on shivering muscles. The exceptional thermogenic potential of BAT is conferred by abundant welldeveloped mitochondria comprising uncoupling protein 1 (UCP1), a protein uncoupling mitochondrial respiration from ATP synthesis (2). BAT is highly vascularized and richly innervated by terminal fibers of the postganglionic neurons of the sympathetic nervous system (1-3).

PET/CT scanning investigations using ${ }^{18} \mathrm{~F}$-fluorodeoxyglucose $\left({ }^{18} \mathrm{FDG}\right)$ have revealed symmetrical cervical, supraclavicular metabolically active fat depots, which were suggested by Hany and colleagues to represent BAT (4-7). These fat depots comprise sympathetically innervated multilocular adipocytes expressing UCP1 (8), the ultimate marker of brown fat cells. The magnitude of ${ }^{18} \mathrm{FDG}$ uptake by BAT was reported to increase with exposure to low temperature, to be higher in women than men, and to decrease with age and body fat mass $(5,7-12)$. These observations tend to support the idea that BAT substantially contributes to energy expenditure $(2,13,14)$. As these observations have only been based on ${ }^{18}$ FDG uptake, however, the studies carried out so far in humans have only allowed speculative conclusions regarding the oxidative capacity/activity of BAT.

Authorship note: Véronique Ouellet and Sébastien M. Labbé contributed equally to the work.

Conflict of interest: The authors have declared that no conflict of interest exists. Citation for this article: J Clin Invest. 2012;122(2):545-552. doi:10.1172/JCI60433.
The present study was thus designed to determine whether BAT is metabolically active and contributes to cold-induced nonshivering thermogenesis in humans. Using PET with ${ }^{11} \mathrm{C}$-acetate (to determine tissue oxidative activity), ${ }^{18} \mathrm{FDG}$ (a glucose analogue), and ${ }^{18} \mathrm{~F}$-fluoro-thiaheptadecanoic acid ( $\left.{ }^{18} \mathrm{FTHA}\right)$, a fatty acid tracer, BAT oxidative metabolism, glucose, and nonesterified fatty acid (NEFA) uptake were quantified in adult humans subjected to cold exposure conditions designed to minimize shivering.

\section{Results}

Six healthy men aged from 23 to 42 years, with a BMI of 23.7 to $31.0 \mathrm{~kg} / \mathrm{m}^{2}$, and taking no medication participated in the present study protocols (Figure 1). During cold exposure, average skin temperature was reduced by $3.8 \pm 0.4^{\circ} \mathrm{C}$ without change in core body temperature, and $\mathrm{VO}_{2}, \mathrm{VCO}_{2}$, and resting energy expenditure increased approximately 1.8 -fold (Table 1). Plasma glucose, triglycerides, triiodothyronine, thyroxin, thyroid-stimulating hormone, cortisol, and ACTH levels did not change significantly with cold exposure, whereas NEFA levels and NEFA rate of appearance in blood increased significantly (Table 1). By design, shivering was controlled and minimized to $1.6 \% \pm 0.5 \%$ (range, $1.1 \%$ to $2.4 \%$ ) of maximal voluntary contraction as continuously recorded by electromyography (EMG) in 4 large muscle groups known to contribute significantly to shivering during cold exposure (15-17).

${ }^{18}$ FDG uptake during the cervicothoracic dynamic PET/CT acquisition upon cold exposure of 1 representative participant is shown in Figure 2A. During cold exposure, fractional uptake $\left(K_{i}\right)$ of ${ }^{18} \mathrm{FDG}$ (Figure 2B) was higher in supraclavicular BAT compared with trapezius and deltoid muscles and subcutaneous adipose tissue but not compared with the longus colli (a small muscle 
A

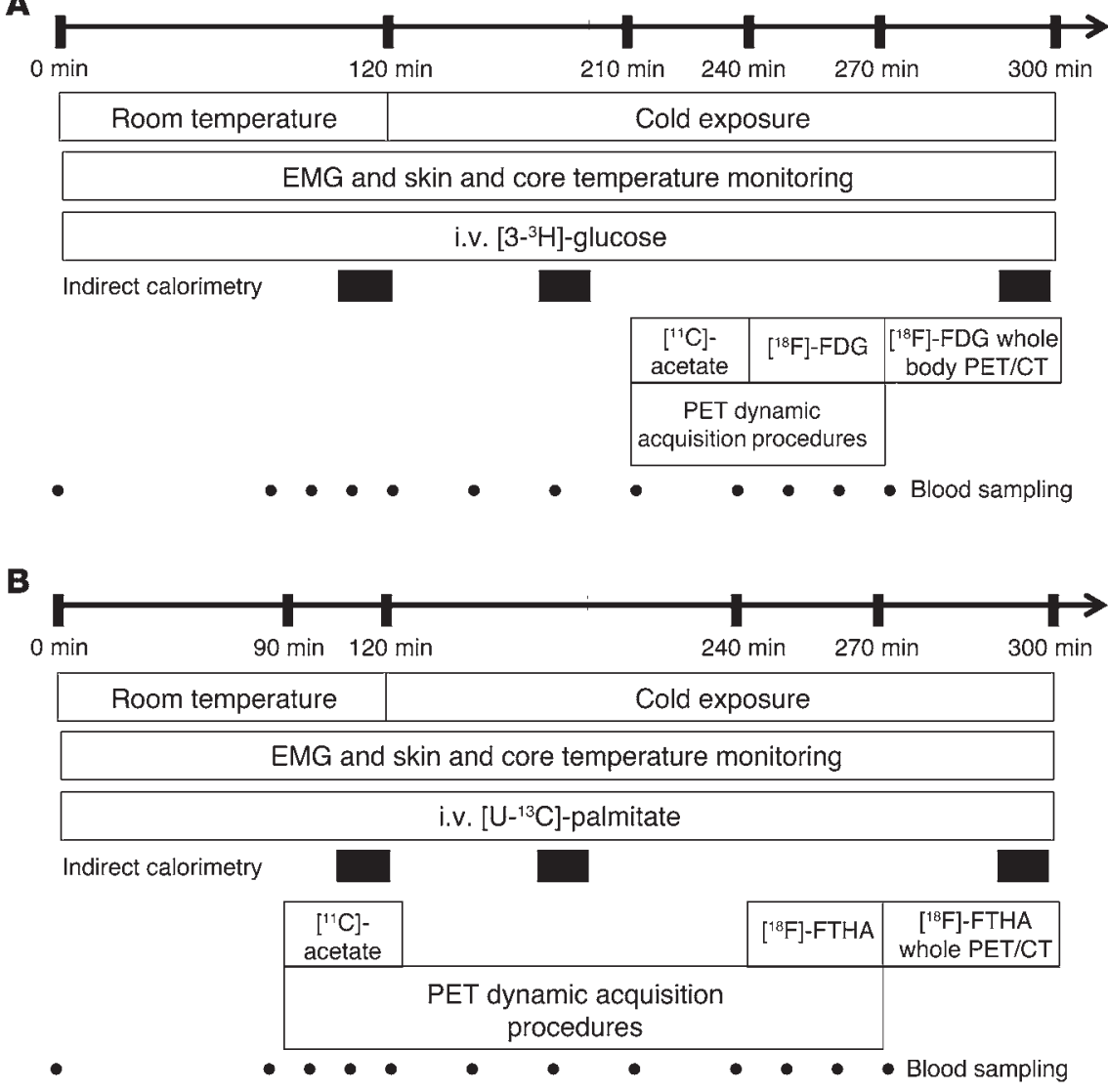

Figure 1

Study protocols. (A) Measurement of plasma glucose turnover and BAT ${ }^{11} \mathrm{C}$-acetate and ${ }^{18} \mathrm{FDG}$ uptake during acute cold exposure. (B) Measurement of plasma NEFA turnover and BAT ${ }^{18} \mathrm{FTHA}$ during acute cold exposure and BAT ${ }^{11} \mathrm{C}$-acetate uptake at room temperature. located on the anterior surface of the cervical spine, between the atlas and the third dorsal vertebra). Net tissue glucose uptake $\left(K_{m}\right)$ (Figure 2C) was higher in BAT vs. subcutaneous adipose tissue, trapezius, and deltoid, but not compared with the longus colli. Whole-body ${ }^{18}$ FDG uptake in one of the participants at the end of the protocol is shown in Figure 2D. BAT mean total volume of activity was $168 \pm 56 \mathrm{ml}$ (range 31 to $329 \mathrm{ml}$ ) based on ${ }^{18} \mathrm{FDG}$ uptake. Glucose uptake by BAT amounted to $10.8 \pm 4.5 \mu \mathrm{mol} / \mathrm{min}$ (range 1.3 to $28.7 \mu \mathrm{mol} / \mathrm{min}$ ). Given a plasma glucose appearance rate of $1,493 \pm 460 \mu \mathrm{mol} / \mathrm{min}$, BAT glucose uptake accounted for $1.3 \% \pm 0.8 \%$ of plasma glucose turnover (range $0.04 \%$ to $5.2 \%$ ).

${ }^{18}$ FTHA uptake during cervicothoracic dynamic PET/CT acquisition upon cold exposure of 1 representative participant is shown in Figure 3A. During cold exposure, fractional uptake $\left(K_{i}\right)$ of ${ }^{18} \mathrm{FTHA}$ (Figure 3B) and net tissue NEFA uptake $\left(K_{m}\right)$ (Figure 3C) were significantly higher in supraclavicular BAT compared with subcutaneous adipose tissue, trapezius, and deltoid, but not different from that of the longus colli. Whole-body ${ }^{18}$ FTHA uptake at the end of the protocol in one of the participants is shown in Figure 3D. NEFA uptake by BAT amounted to $2.3 \pm 0.8 \mu \mathrm{mol} / \mathrm{min}$ (range, 0.3 to 4.4 $\mu \mathrm{mol} / \mathrm{min}$ ). Given a plasma NEFA appearance rate of $1,002 \pm 72$ $\mu \mathrm{mol} / \mathrm{min}$, BAT NEFA uptake accounted for approximately $0.25 \% \pm 0.08 \%$ of plasma NEFA turnover (range, $0.04 \%$ to $0.44 \%$ ).

After i.v. injection of ${ }^{11} \mathrm{C}$-acetate, blood ${ }^{11} \mathrm{C}$ radioactivity over time was not significantly different during cold exposure compared with at room temperature (Figure 4A). BAT (Figure 4B), but not subcutaneous adipose tissue (Figure $4 \mathrm{C}$ ), ${ }^{11} \mathrm{C}$ radioactivity was increased throughout exposure to cold. The longi colli
(Figure 4D) and sternocleidomastoids (not shown) were the only cervical and upper thoracic muscles that displayed significant cold-induced increase in ${ }^{11} \mathrm{C}$ radioactivity over time. ${ }^{11} \mathrm{C}$ radioactivity over time in trapezius and deltoids is shown in Figure 4, $\mathrm{E}$ and $\mathrm{F}$, respectively. The $\mathrm{AUC}$ of ${ }^{11} \mathrm{C}$ radioactivity, a marker of tissue oxidative and/or nonoxidative metabolism (acetate retention), was elevated in BAT and longus colli. The monoexponential decay slope from tissue peak ${ }^{11} \mathrm{C}$ activity $\left({ }^{11} \mathrm{C}\right.$-acetate $\left.k\right)$, a valid surrogate of tissue oxidative metabolism $(18,19)$, was, however, increased in BAT in all participants (Figure 4G) but not in longus colli (Figure $4 \mathrm{H}$ ), demonstrating that the former tissue plays an important role in cold-induced nonshivering thermogenesis, whereas the latter tissue mostly retained acetate in nonoxidative pathways. BAT CT radio density (in Hounsfield units) increased in all participants (by $17 \% \pm 5 \%$; range, $6 \%$ to $41 \%$; $P=0.03$ ) (Figure $4 \mathrm{I}$ ), whereas white adipose tissue (WAT) radio density did not change $(3 \% \pm 5 \% ; P=1.00)$. Supplemental Figure 1 (supplemental material available online with this article; doi:10.1172/ JCI60433DS1) shows actual CT and PET/CT fusion images of the integrated tissue activity in the neck and upper chest area from dynamic list-mode acquisitions at room temperature and during cold exposure in one of the participants.

There was a significant inverse correlation between BAT volume of activity and shivering expressed as percentage of voluntary maximal contraction (Spearman $r=-0.89 ; P=0.03$ ) (Supplemental Figure 2). We found no other significant correlations between BAT volume of activity and energy expenditure (Supplemental Table 1), although our small sample size severely limits the power of these analyses. 


\section{Table 1}

Average body temperatures, indirect calorimetry, circulating metabolites and hormones, and plasma glucose and NEFA appearance rates at ambient temperature (warm) and during cold exposure (cold)

\begin{tabular}{|c|c|c|c|c|c|c|c|c|}
\hline & & 1 & 2 & 3 & 4 & 5 & 6 & Mean \pm SEM \\
\hline \multirow[t]{2}{*}{ Skin temperature $\left({ }^{\circ} \mathrm{C}\right)$} & Warm & 32.9 & 33.1 & 32.6 & 34.2 & 33.1 & 32.7 & $33.1 \pm 0.2$ \\
\hline & Cold & 28.2 & 30.5 & 28.5 & 30.7 & 29.2 & 28.2 & $29.6 \pm 0.4^{A}$ \\
\hline \multirow[t]{2}{*}{ Core temperature $\left({ }^{\circ} \mathrm{C}\right)$} & Warm & 37.0 & 37.0 & 37.4 & 37.0 & 36.6 & 36.6 & $37.0 \pm 0.1$ \\
\hline & Cold & 36.4 & 36.4 & 37.4 & 36.8 & 36.2 & 36.7 & $36.6 \pm 0.2$ \\
\hline \multirow[t]{2}{*}{$\mathrm{VO}_{2}(\mathrm{I} / \mathrm{min})$} & Warm & 0.318 & 0.346 & 0.356 & 0.375 & 0.386 & 0.441 & $0.370 \pm 0.017$ \\
\hline & Cold & 0.563 & 0.661 & 0.473 & 0.615 & 0.678 & 0.923 & $0.652 \pm 0.062^{\mathrm{A}}$ \\
\hline \multirow[t]{2}{*}{$\mathrm{VCO}_{2}(\mathrm{l} / \mathrm{min})$} & Warm & 0.275 & 0.302 & 0.320 & 0.324 & 0.310 & 0.390 & $0.320 \pm 0.016$ \\
\hline & Cold & 0.503 & 0.643 & 0.431 & 0.497 & 0.535 & 0.893 & $0.584 \pm 0.068^{A}$ \\
\hline \multirow[t]{2}{*}{ TEE (kcal/min) } & Warm & 1.54 & 1.69 & 1.75 & 1.82 & 1.85 & 2.15 & $1.80 \pm 0.08$ \\
\hline & Cold & 2.76 & 3.29 & 2.33 & 2.95 & 3.24 & 4.59 & $3.19 \pm 0.31^{A}$ \\
\hline \multirow[t]{2}{*}{ Glucose (mmol/l) } & Warm & 3.7 & 4.4 & 4.1 & 3.3 & 4.2 & 4.0 & $4.0 \pm 0.2$ \\
\hline & Cold & 3.8 & 4.5 & 3.7 & 3.9 & 4.2 & 3.9 & $4.0 \pm 0.1$ \\
\hline \multirow{2}{*}{$\mathrm{Ra}_{\text {glucose }}(\mu \mathrm{mol} / \mathrm{min})$} & Warm & ND & ND & ND & ND & ND & ND & ND \\
\hline & Cold & 950 & 957 & 1,133 & 1,703 & 3,661 & 556 & $1,493 \pm 460$ \\
\hline \multirow[t]{2}{*}{ Insulin (pmol/l) } & Warm & 65 & 67 & 74 & 53 & 45 & 125 & $71 \pm 11$ \\
\hline & Cold & 69 & 62 & 45 & 57 & 62 & 84 & $63 \pm 5$ \\
\hline \multirow[t]{2}{*}{$\mathrm{TG}(\mathrm{mmol} / \mathrm{l})$} & Warm & 0.88 & 0.87 & 1.52 & 0.69 & 0.49 & 1.15 & $0.93 \pm 0.15$ \\
\hline & Cold & 0.89 & 0.78 & 1.61 & 0.62 & 0.57 & 1.06 & $0.92 \pm 0.16$ \\
\hline \multirow[t]{2}{*}{ NEFA ( $\mu \mathrm{mol} / \mathrm{min})$} & Warm & 366 & 352 & 645 & 689 & 311 & 484 & $474 \pm 66$ \\
\hline & Cold & 475 & 535 & 805 & 897 & 476 & 677 & $644 \pm 73^{A}$ \\
\hline \multirow[t]{2}{*}{$\operatorname{Ra}_{\text {NEFA }}(\mu \mathrm{mol} / \mathrm{min})$} & Warm & 708 & ND & 740 & 845 & 759 & 813 & $773 \pm 25$ \\
\hline & Cold & 901 & ND & 937 & 1,011 & 884 & 1,278 & $1,002 \pm 72^{A}$ \\
\hline \multirow[t]{2}{*}{ TSH (IU/I) } & Warm & 0.91 & 1.59 & 0.87 & 2.21 & 1.72 & 0.97 & $1.38 \pm 0.22$ \\
\hline & Cold & 0.91 & 1.66 & 0.80 & 2.17 & 1.59 & 0.93 & $1.34 \pm 0.22$ \\
\hline \multirow[t]{2}{*}{ Free T3 (pmol/l) } & Warm & 5.3 & 4.6 & 5.2 & 5.9 & 5.7 & 6.1 & $5.5 \pm 0.2$ \\
\hline & Cold & 5.0 & 4.6 & 5.2 & 6.0 & 5.5 & 6.2 & $5.4 \pm 0.2$ \\
\hline \multirow[t]{2}{*}{ Free T4 (pmol/l) } & Warm & 18.3 & 18.1 & 17.1 & 16.5 & 16.2 & 17.2 & $17.2 \pm 0.4$ \\
\hline & Cold & 18.6 & 18.9 & 17.6 & 15.8 & 16.7 & 17.8 & $17.5 \pm 0.5$ \\
\hline \multirow[t]{2}{*}{ Cortisol (nmol/l) } & Warm & 216 & 277 & 184 & 237 & 274 & 257 & $241 \pm 15$ \\
\hline & Cold & 256 & 284 & 197 & 255 & 269 & 302 & $206 \pm 15$ \\
\hline \multirow[t]{2}{*}{ BAT $K_{i}{ }^{18} \mathrm{FDG}$} & Warm & ND & ND & ND & ND & ND & ND & ND \\
\hline & Cold & 0.013 & 0.009 & 0.009 & 0.019 & 0.011 & 0.027 & $0.015 \pm 0.003$ \\
\hline \multirow[t]{2}{*}{ BAT $K_{i}{ }^{18} \mathrm{FTHA}$} & Warm & ND & ND & ND & ND & ND & ND & ND \\
\hline & Cold & 0.018 & 0.013 & 0.015 & 0.022 & 0.020 & 0.023 & $0.018 \pm 0.002$ \\
\hline \multirow{2}{*}{$\begin{array}{l}\text { BAT volume } \\
\text { of activity (ml) }\end{array}$} & Warm & ND & ND & ND & ND & ND & ND & ND \\
\hline & Cold & 329 & 57 & 51 & 244 & 31 & 296 & $168 \pm 56$ \\
\hline
\end{tabular}

Values from all participants at ambient temperature (between times 80 and 120 minutes) and during cold exposure (between times 180 and 300 minutes) were averaged from both protocols (no difference between protocol $A$ and $B$ ), except for Raglucose and Ra $a_{N E F A}$, which were only determined in protocol $A$ and $B$, respectively, at isotopic steady-state enrichment (between times 100 and 120 minutes and times 280 and 300 minutes). ${ }^{A} P<0.05$ by Wilcoxon's test. BAT, supraclavicular BAT; Ra, rate of appearance; T3, triiodothyronine; T4, thyroxine.

\section{Discussion}

Based on ${ }^{11} \mathrm{C}$-acetate tissue kinetics, the present results demonstrate significant cold-induced activation of BAT oxidative metabolism in all subjects studied under well-controlled cold exposure conditions designed to minimize shivering. We also determined for what we believe is the first time in vivo in humans that plasma NEFA uptake is increased in cold-activated BAT compared with resting skeletal muscles and subcutaneous adipose tissues.

A cold-induced total BAT glucose uptake averaging $10.8 \pm 2.9$ $\mu \mathrm{mol} / \mathrm{min}$ lies within the range reported by Virtanen et al. (6). In addition, the present results demonstrate the ability of human BAT to also increase its NEFA uptake during cold exposure. Whole-body ${ }^{18}$ FTHA uptake at the end of the protocol predicts NEFA uptake by BAT amounting to $2.3 \pm 0.8 \mu \mathrm{mol} / \mathrm{min}$ (range, 0.3 to $4.4 \mu \mathrm{mol} / \mathrm{min}$ ). One limitation of our experimental design was the impossibility of assessing ${ }^{18} \mathrm{FDG}$ and ${ }^{18} \mathrm{FTHA}$ BAT uptake at ambient temperature, given the complexity of design and acceptable limits of radiation exposure of research participants. However, significant BAT glucose and NEFA uptake is not detectable in the vast majority of individuals at ambient temperature (12, 20). In rodents, the contribution from glucose and NEFA uptake has proven to be a relatively small fraction of total BAT metabolism during acute cold-induced thermogenesis compared with intracellular brown adipocyte triglycerides (21). Also, we did not assess BAT utilization of fatty acids from circulating lipoproteins, another potential source of BAT energy substrates (22). However, unlike what has been observed in mice in the latter study, we did not find any reduction in circulating triglycerides in the present study (Table 1). Assuming a volume of distribution of $0.45 \mathrm{dl} / \mathrm{kg}$ of body weight (23), with an average body weight of $80.7 \mathrm{~kg}$ and a plasma triglyceride level of $0.93 \mathrm{mmol} / \mathrm{l}(82 \mathrm{mg} / \mathrm{dl})$, mean total circulating triglyceride content is estimated at approximately $3 \mathrm{~g}$ 
A

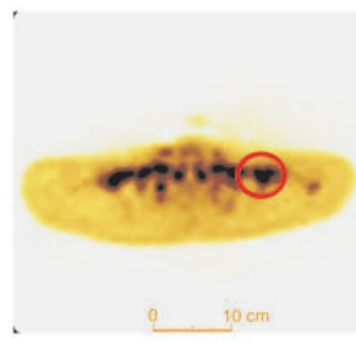

B

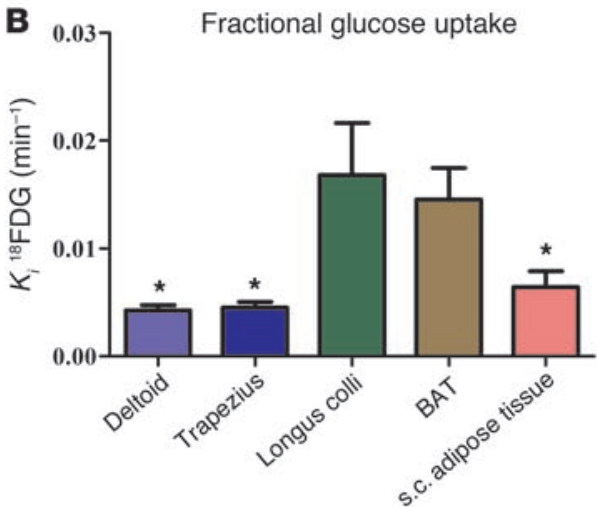

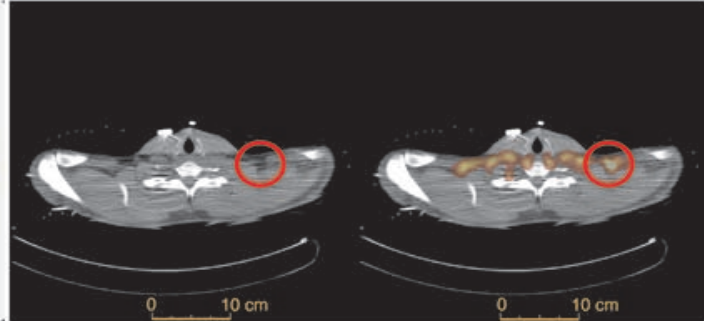

C

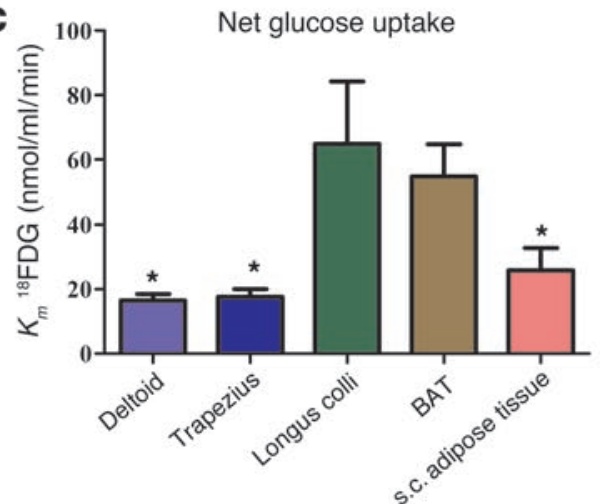

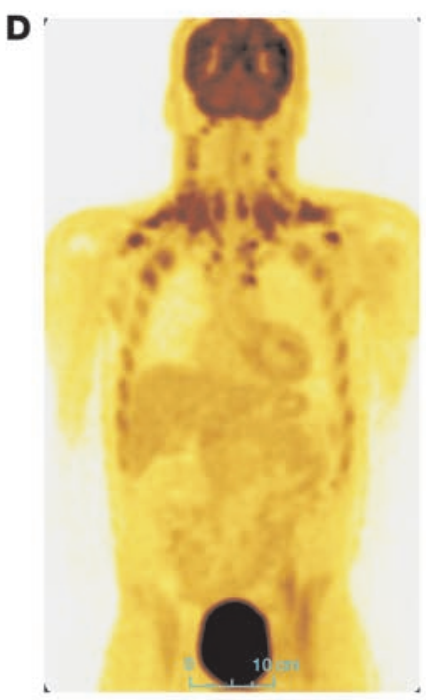

Figure 2

Tissue glucose uptake. (A) Transversal PET (left panel), CT (middle panel), and fusion scan (right panel) views of the cervicothoracic junction in one of the participants. Red circles denote supraclavicular BAT. (B) Fractional $\left(K_{i}\right)$ and $(\mathbf{C})$ net $\left(K_{m}\right)$ glucose uptake in cervicothoracic tissues. (D) Coronal view (postero-anterior projection) of whole-body ${ }^{18} \mathrm{FDG}$ uptake during cold exposure. ${ }^{*} P<0.05$ versus BAT, ANOVA with Dunnett's post-hoc test.

in the participants of the present study. As the half-life of circulating triglycerides during fasting (mostly VLDL) is relatively long (approximately 2 hours, i.e., a fractional clearance rate of $0.5 / \mathrm{h}$; ref. 23) compared with the length of cold exposure in the present study, it is very unlikely that the pool of circulating triglycerides, even if it was fully utilized, could account for the 250 extra $\mathrm{kcal}$ of energy expenditure observed (i.e., approximately $28 \mathrm{~g}$ of triglycerides). It is also noteworthy that our subjects were not, in contrast with the mice in Bartelt's study (22), adapted to a temperature below thermoneutrality, which may render BAT adipocytes more prepared to clear circulating glucose and lipid.

The 6 subjects of the present study all exhibited increases in BAT metabolism upon cold exposure, albeit to varying degrees. The variability in the response occurred despite application of a cold exposure protocol that not only restricted shivering, but also dictated the strength of the cold response from strict body and skin temperature monitoring and indirect calorimetry measurements. Such variation would seem to be accounted for by interindividual differences in BAT capacity (volume). The wide interindividual differences in detectable BAT volume of activity (from to 31 to $329 \mathrm{ml}$ ) observed in young healthy men in the present study suggests that unknown factors may modulate BAT volume and thermogenic capacity in addition to age, sex, body mass index, and diabetes (24). Furthermore, we found a significant inverse relationship between BAT volume of activity and shivering. Interestingly, BAT precursor cells are present in supraclavicular fat independently of the presence of spontaneous ${ }^{18}$ FDG uptake (25). Of note, a very recent publication demonstrated cold-induced increased blood flow in BAT that was associated with increased energy expenditure (26). The latter is con- sistent with the present results, which demonstrate cold-induced BAT thermogenesis in humans.

Our demonstration of BAT oxidative metabolism with trivial rates of plasma glucose and NEFA utilization and rapid increase in BAT radio density during cold exposure is suggestive of increased intracellular triglyceride utilization as the main source of energy for BAT thermogenesis. Intracellular triglycerides are the main fuel to sustain BAT energy metabolism during cold exposure in animal models $(2,27,28)$. In room temperature-acclimated rats, short-term acute exposure to cold has been reported to lead to a near-complete depletion of BAT lipid (28). A similar depletion of BAT lipid has been reported at necropsy in newborn infants and adults who died from hypothermia (27). Intracellular brown adipocyte triglycerides represent half of the brown adipocyte volume (27). From a mass of $168 \mathrm{~g}$ (the average BAT mass seen in the present study), one can predict a BAT fat content of approximately $84 \mathrm{~g}$. Mobilization of one-third of that lipid reserve ( $28 \mathrm{~g})$, which seems possible based on previous investigations (28), would be sufficient to account for the extra energy $(250 \pm 45 \mathrm{kcal})$ expended during the 3 -hour period of cold exposure in the present study. Although the $80 \%$ increase in total energy expenditure (TEE) that we observed during acute cold exposure appears important, it is therefore very likely that BAT thermogenesis accounted for an important fraction of this increase in TEE. Future studies will need to determine the contribution of intracellular triglycerides to BAT thermogenesis.

In addition, we cannot exclude the contribution of other tissues to cold-induced thermogenesis. We recorded increased glucose, NEFA, and acetate uptake in the longus colli. Nonetheless, the observation that significant cold-induced increase in ${ }^{11} \mathrm{C}$-acetate oxidative metabolism was only seen in BAT demonstrates a signifi- 
A

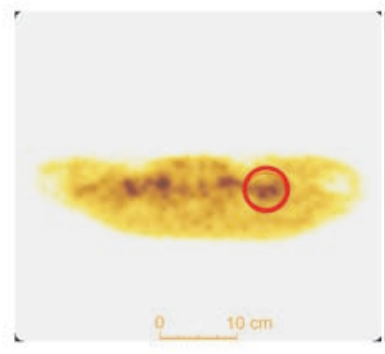

B

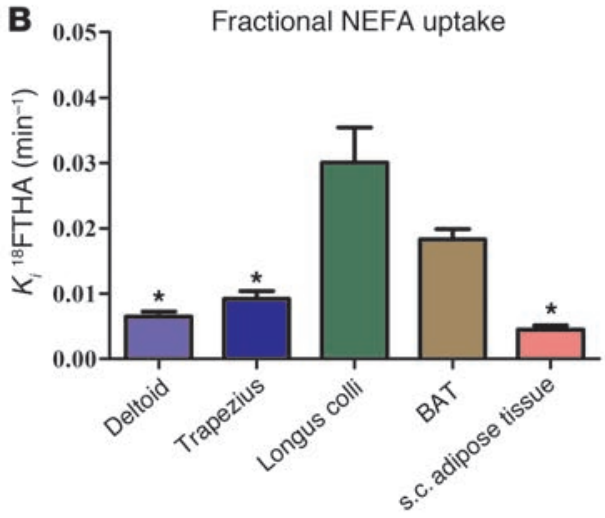

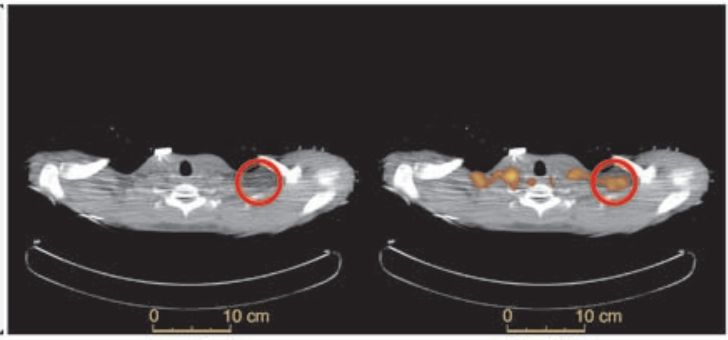

C

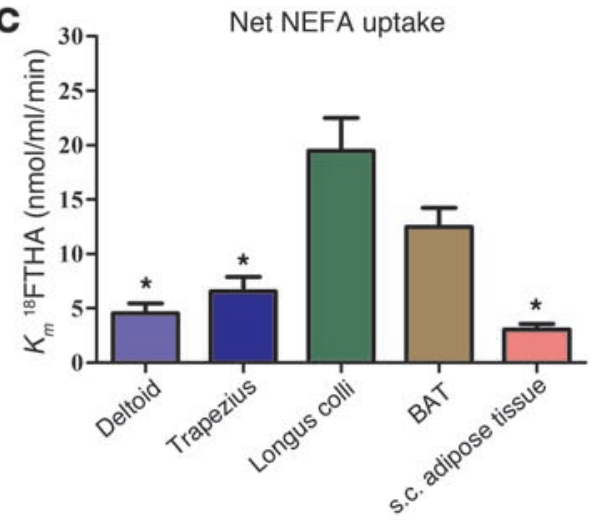

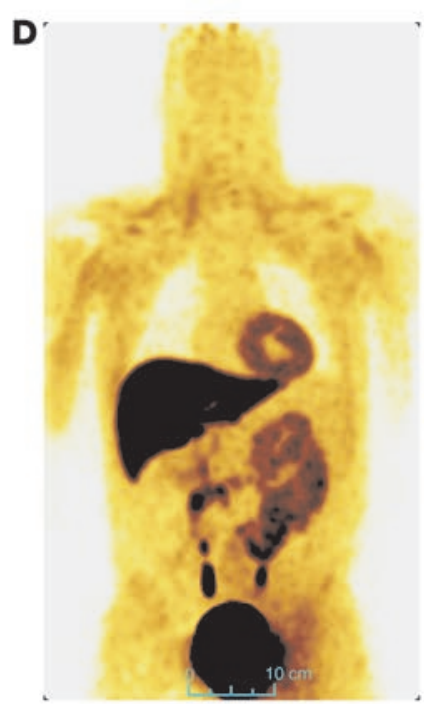

Figure 3

Tissue NEFA uptake. (A) Transversal PET (left panel), CT (middle panel), and fusion scan (right panel) views of the cervicothoracic junction in one of the participants. Red circles show supraclavicular BAT. (B) Fractional $\left(K_{i}\right)$ and $(\mathbf{C})$ net $\left(K_{m}\right)$ NEFA uptake in cervicothoracic tissues. (D) Coronal view (postero-anterior projection) of whole-body ${ }^{18} \mathrm{FTHA}$ uptake during cold exposure. ${ }^{\star} P<0.05$ versus BAT, ANOVA with Dunnett's post-hoc test.

cant role of this tissue in the nonshivering thermogenic response to cold. The limited field of view of our PET/CT scanner $(18 \mathrm{~cm}$ length) during dynamic acquisitions prevents us from assessing oxidative metabolism from the ${ }^{11} \mathrm{C}$-acetate method in other internal organs, such as the heart and other deep central muscles that might have been activated by cold. The number of subjects in the present study is small due to the complexity of our measurements. Despite this limitation, we are nonetheless confident that our findings apply to other populations, since they were very consistent between subjects. Finally, it is not possible to exclude an effect of the 2-hour daily time difference in ${ }^{11} \mathrm{C}$-acetate injection between the 2 protocols in the present study. To our knowledge, the effect of nycthemeral cycle on BAT metabolism has not been previously studied in humans.

The present findings support a role of BAT for nonshivering thermogenesis in humans with intracellular triglycerides as the main source of energy for this process, as observed in rodents. However, it remains to be demonstrated whether chronic and frequent bouts of cold exposure may contribute to increase BAT capacity and/or activity and may be a viable adjunct therapeutic strategy to other lifestyle interventions to prevent or treat obesity and its metabolic complications. It is also possible that energy substrate uptake by BAT could be substantially increased once intracellular triglyceride stores are depleted and/or BAT is fully cold adapted, as recently shown in rodents (22). Quantitative assessment of the contribution of intracellular triglyceride oxidation in BAT thermogenesis awaits further methodological developments.

In summary, the present study demonstrates that a cold-exposure stimulus designed to minimize muscle-mediated shivering thermogenesis enhances BAT oxidative metabolism as well as glucose and NEFA uptake in adult humans. The enhanced BAT activity was associated with a 1.8-fold increase in whole-body energy expenditure. We found a significant inverse relationship between BAT volume of activity and shivering and a significant increase in BAT radio density within 3 hours of cold exposure, indicating rapid reduction in BAT triglyceride content. The present results demonstrate that BAT is undoubtedly involved in nonshivering thermogenesis in humans.

\section{Methods}

Protocols A and B were 4.5-hour metabolic tests performed in random order, within an average of 20 days of each other (range, 7 to 36 days) and designed to assess whole-body and BAT-specific energy substrate turnover and oxidation and energy expenditure at room temperature $\left(\sim 25^{\circ} \mathrm{C}\right.$, time 0 to 120 minutes) and during acute exposure to cold (time 120 to 270 minutes) (Figure 1). Participants were instrumented and fitted with a liquid-conditioned tube suit (Allen-Vanguard Inc.). Following the room temperature period (time 0 to 120 minutes), the liquid-conditioned tube suit was perfused with approximately $18^{\circ} \mathrm{C}$ water using a temperature and flow-controlled circulation bath (Endocal, NESLAB, and Model 200-00; Micropump Inc.). Briefly, the same suit was used for all subjects to maintain consistent tubing density. In addition, the flow and temperature of water through the suit was produced with the same cooling bath. Based on pilot experiments, we determined that circulating water in the suit at $18^{\circ} \mathrm{C}$ minimized overt shivering in healthy participants while achieving a significant reduction in skin temperature of at least $2.5^{\circ} \mathrm{C}$. We did not try to avoid the slight but significant increase in electromyographic (EMG) activity observed during the experiments. Therefore, EMG activity could 

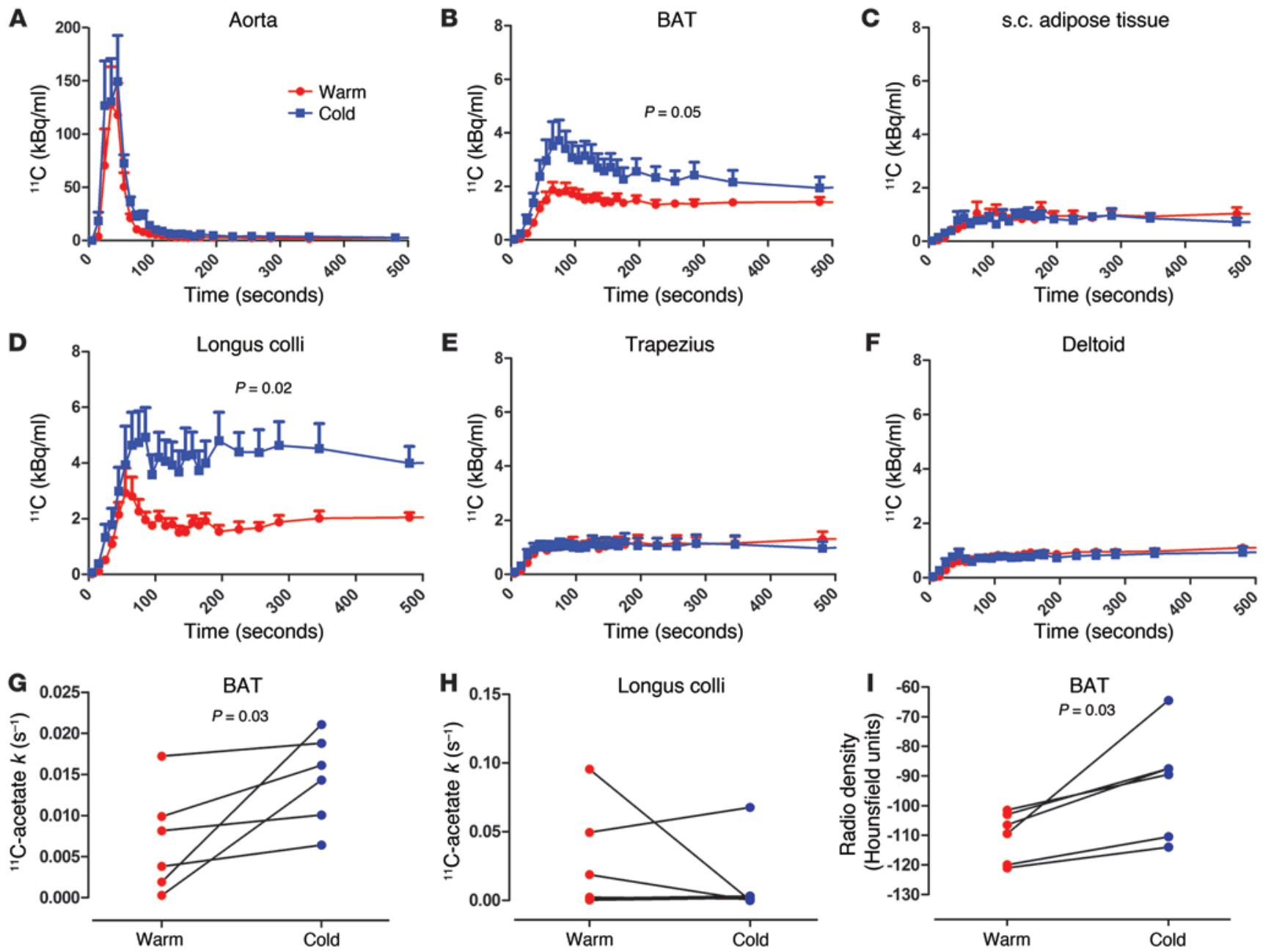

Figure 4

${ }^{11} \mathrm{C}$-acetate kinetics. ${ }^{11} \mathrm{C}$ time-radioactivity curves over the first 500 seconds of acquisition after ${ }^{11} \mathrm{C}$-acetate injection at room temperature (red) and during cold exposure (blue) in (A) blood in the aorta, (B) supraclavicular BAT, (C) subcutaneous adipose tissue, (D) longus colli, (E) trapezius, and $(\mathbf{F})$ deltoid. ${ }^{11} \mathrm{C}$ time-radioactivity curves were different during cold exposure from those at room temperature in BAT (2-way ANOVA, $P=0.05$; interaction with time, $P<0.001$ ) and in longi colli (2-way ANOVA, $P=0.02$; interaction with time, $P<0.001$ ), but not in other organs. Monoexponential decay slope from peak tissue ${ }^{11} \mathrm{C}$ activity $\left({ }^{11} \mathrm{C}\right.$-acetate $k$ ) in $(\mathbf{G})$ supraclavicular BAT and $(\mathbf{H})$ longus colli. (I) BAT radio density by CT.

slightly differ among individuals despite similar cold exposure, depending on their degree of nonshivering thermogenesis. This difference in extent of EMG activity thus masked any possibility of discerning a correlation between nonshivering thermogenesis and TEE. Change in total heat production was calculated by indirect calorimetry ( $V_{\max } 29 n$; Sensormedics) (29) at room temperature and between times of 180 to 200 minutes and 280 to 300 minutes (i.e., 60 to 80 minutes and 160 to 180 minutes after the beginning of cold exposure). TEE rapidly increased by time 180 to 200 minutes to approximately $79 \%$ of that recorded between times 280 and 300 minutes. Only indirect calorimetry and EMG measurements during the latter period are reported. Dry heat loss from the difference between water temperature entering and exiting the tube suit at a given flow rate was determined (30). Skin and core temperatures were monitored as previously described $(31,32)$. Changes in whole-body heat production, heat loss, and core and mean skin temperatures as well as muscle shivering intensity by EMG were determined as previously described $(15,16,33,34)$. This protocol achieved consistent skin temperature (difference $=-0.2 \pm 0.3^{\circ} \mathrm{C}$ ) and energy expenditure (difference $2.2 \% \pm 7.0 \%$ ) between protocols $\mathrm{A}$ and B during cold exposure.

Plasma glucose appearance rate $\left(\mathrm{Ra}_{\text {glucose }}\right)$ was determined using a primed continuous infusion $\left(0.33 \times 10^{6} \mathrm{dpm} / \mathrm{min}\right)$ of $\left[3-{ }^{3} \mathrm{H}\right]$-glucose during protocol A (23). Ra $a_{\text {NEFA }}$ was measured using i.v. administration of [U-13 C]-palmitate during protocol B using the Steele steady-state equation, as previously described $(29,35)$. Tissue oxidative metabolism was determined after i.v. bolus injection of ${ }^{11} \mathrm{C}$-acetate $(\sim 185 \mathrm{MBq})$ at time 90 minutes (room temperature) and at time 210 minutes (i.e., 90 minutes after onset of cold exposure), followed by 30 -minute list-mode dynamic PET acquisition, preceded by a $40 \mathrm{mAs}$ CT acquisition centered at the cervicothoracic junction, as described (20). Tissue oxidative metabolism index (the rapid fractional tissue clearance of ${ }^{11} \mathrm{C}$-acetate, $k$, in $\mathrm{s}^{-1}$ ) was estimated from tissue ${ }^{11} \mathrm{C}$ activity over time using monoexponential fit from the time of peak tissue activity (36). This method is based on the following assumptions (37): (a) acetate enters the Krebs cycle freely after rapid conversion into acetyl-CoA; (b) other acetate metabolic fates (e.g., de novo lipogenesis) are relatively 
slow compared with the Krebs cycle carbon fluxes; (c) carbon fluxes into the Krebs cycle through acetyl-CoA are directly coupled to the production of reducing equivalents; (d) the Krebs cycle contribution to the production of reducing equivalents is stable and accounts for approximately twothirds of total production; and (e) the production of reducing equivalents is tightly coupled to oxygen consumption.

In protocol A, each participant received an i.v. bolus of ${ }^{18} \mathrm{FDG}(\sim 185$ $\mathrm{MBq}$ ) at time 240 minutes (i.e., 2 hours after the onset of cold exposure), with 30 minutes list-mode dynamic PET acquisition centered at the cervicothoracic junction to determine tissue glucose uptake using Patlak graphical analysis (38). This was followed by a whole-body CT scan (16 $\mathrm{mAs}$ ) to correct for attenuation and for definition of PET regions of interest, followed by whole-body PET acquisition to determine whole-body ${ }^{18} \mathrm{FDG}$ uptake. In protocol $\mathrm{B}$, the same procedure was performed, but with i.v. bolus administration of ${ }^{18}$ FTHA $(\sim 185 \mathrm{MBq})$ instead of ${ }^{18} \mathrm{FDG}$ to determine tissue NEFA uptake after correction for plasma metabolites using Patlak linearization $(20,38,39)$. For dynamic PET acquisitions, mean value of pixels (mean standard uptake value [SUV]) for each frame was recorded. Regions of interest were drawn on the aortic arch for blood activity (input functions) and on supraclavicular BAT according to the following criteria: a tissue radio density between -10 and -100 Hounsfield units and ${ }^{18} \mathrm{FDG}$ uptake during cold exposure of more than 1 SUV unit (12). We also calculated total BAT volume of activity on whole-body scans according to the later criteria, as previously described (12). The regions of interest (ROI) were first defined from the transaxial CT slices, then copied to ${ }^{18} \mathrm{FDG}$, and then to ${ }^{11} \mathrm{C}$-acetate and ${ }^{18} \mathrm{FTHA}$ image sequences. For whole-body scans, mean values of pixels (mean SUV) for all tissues of interest were recorded. In the cervicothoracic dynamic sequences, ROI were drawn on the 2 largest muscles in the field of view (deltoid and trapezius, the latter also being electromyographically recorded), on posterior cervical subcutaneous adipose tissue, and on any muscle or tissue structures that showed significant ( $>1$ SUV unit) ${ }^{18}$ FDG uptake during cold exposure. The latter occurred systematically only in small paraspinal muscles of the neck (longi colli) within the field of view of dynamic scans.

Statistics. Data are expressed as mean + SEM. Wilcoxon's test was used to compare characteristics and averaged steady-state hormone and metabolite levels between room temperature and cold exposure. Two-way ANOVA for repeated measures with temperature, time, and interaction as the independent variables was used to analyze time- and temperature-dependent differences in blood and tissue PET-acquired activities throughout the protocols. ANOVA for repeated measures with Dunnett's post-hoc test were performed to compare fractional and net glucose and NEFA uptake between BAT and other tissues during cold exposure. Appropriate transformation of variables was performed when normal distribution was not observed for parametric statistical testing. A 2-tailed $P$ value of less than 0.05 was considered significant. All analyses were performed with the GraphPad Prism version 5.00 for Windows.

Study approval. Informed written consent was obtained from all participants in accordance with the Declaration of Helsinki, and the protocol received approval from the Human Ethics Committee of the Centre de recherche clinique Etienne-LeBel.

\section{Acknowledgments}

This work was supported by a grant from the Canadian Diabetes Association (OG-3-10-2970-AC) and was performed at the Centre de recherche clinique Etienne-Le Bel, a research center funded by the Fonds de la recherche en santé du Québec (FRSQ). S.M. Labbé is the recipient of a Canadian Diabetes Association Doctoral Studentship Award. D. Richard is the recipient of the CIHR/Merck Frosst Research Chair on Obesity. A.C. Carpentier was the recipient of a FRSQ Senior Scholarship Award and is now the recipient of the CIHR-GlaxoSmithKline Chair in Diabetes.

Received for publication August 10, 2011, and accepted in revised form November 16, 2011.

Address correspondence to: André C. Carpentier, Division of Endocrinology, Centre hospitalier universitaire de Sherbrooke, Sherbrooke, Québec, Canada J1H 5N4. Phone: 819.564.5244; Fax: 819.564.5292; E-mail: andre.carpentier@usherbrooke.ca. Or to: Denis Richard, Centre de recherche de l'Institut universitaire de cardiologie et de pneumologie de Québec, Quebec City, Québec, Canada. Phone: 418.656.8711, ext. 11714; Fax: 418.656.4929; E-mail: Denis.Richard@criucpq.ulaval.ca.
1. Cannon B, Nedergaard J. Brown adipose tissue: function and physiological significance. Physiol Rev. 2004;84(1):277-359.

2. Richard D, Picard F. Brown fat biology and thermogenesis. Front Biosci. 2011;16:1233-1260.

3. Sell H, Deshaies Y, Richard D. The brown adipocyte: update on its metabolic role. Int J Biochem Cell Biol. 2004;36(11):2098-2104.

4. Hany TF, Gharehpapagh E, Kamel EM, Buck A, Himms-Hagen J, von Schulthess GK. Brown adipose tissue: a factor to consider in symmetrical tracer uptake in the neck and upper chest region. EurJ Nucl Med Mol Imaging. 2002;29(10):1393-1398.

5. Cypess AM, et al. Identification and importance of brown adipose tissue in adult humans. $N$ Engl J Med. 2009;360(15):1509-1517.

6. Virtanen KA, et al. Functional brown adipose tissue in healthy adults. $N$ Engl J Med. 2009; 360(15):1518-1525.

7. Saito M, et al. High incidence of metabolically active brown adipose tissue in healthy adult humans: effects of cold exposure and adiposity. Diabetes. 2009;58(7):1526-1531.

8. Zingaretti MC, et al. The presence of UCP1 demonstrates that metabolically active adipose tissue in the neck of adult humans truly represents brown adipose tissue. FASEB J. 2009;23(9):3113-3120.

9. Cohade C, Mourtzikos KA, Wahl RL. "USA-Fat": prevalence is related to ambient outdoor tempera- ture-evaluation with 18F-FDG PET/CT. J Nucl Med. 2003;44(8):1267-1270.

10. Garcia CA, et al. Reduction of brown fat 2-deoxy-2[F-18]fluoro-D-glucose uptake by controlling environmental temperature prior to positron emission tomography scan. Mol Imaging Biol. 2006;8(1):24-29.

11. Kim S, Krynyckyi BR, Machac J, Kim CK. Temporal relation between temperature change and FDG uptake in brown adipose tissue. Eur J Nucl Med Mol Imaging. 2008;35(5):984-989.

12. Ouellet V, et al. Outdoor temperature, age, sex, body mass index, and diabetic status determine the prevalence, mass, and glucose-uptake activity of 18F-FDG-detected BAT in humans. J Clin Endocrinol Metab. 2011;96(1):192-199.

13. Cannon B, Nedergaard J. Metabolic consequences of the presence or absence of the thermogenic capacity of brown adipose tissue in mice (and probably in humans). Int J Obes (Lond). 2010;34(suppl 1):S7-S16.

14. Enerback S. Human brown adipose tissue. Cell Metab. 2010;11(4):248-252.

15. Haman F, Legault SR, Weber JM. Fuel selection during intense shivering in humans: EMG pattern reflects carbohydrate oxidation. J Physiol. 2004;556(pt 1):305-313.

16. Haman F, Legault SR, Rakobowchuk M, Ducharme MB, Weber JM. Effects of carbohydrate availability on sustained shivering II. Relating muscle recruitment to fuel selection. J Appl Physiol. 2004;96(1):41-49.
17. Haman F, Blondin DP, Imbeault MA, Maneshi A. Metabolic requirements of shivering humans. Front Biosci (Schol Ed). 2010;2:1155-1168.

18. Brown M, Marshall DR, Sobel BE, Bergmann SR. Delineation of myocardial oxygen utilization with carbon-11-labeled acetate. Circulation. 1987; 76(3):687-696

19. Ng CK, Huang SC, Schelbert HR, Buxton DB. Validation of a model for [1-11C]acetate as a tracer of cardiac oxidative metabolism. Am J Physiol. 1994; 266(4 pt 2):H1304-H1315.

20. Labbe SM, et al. Normal postprandial nonesterified Fatty Acid uptake in muscles despite increased circulating Fatty acids in type 2 diabetes. Diabetes. 2011;60(2):408-415.

21. Ma SW, Foster DO. Uptake of glucose and release of fatty acids and glycerol by rat brown adipose tissue in vivo. Can J Physiol Pharmacol. 1986;64(5):609-614.

22. Bartelt $A$, et al. Brown adipose tissue activity controls triglyceride clearance. Nat Med. 2011;17(2):200-205.

23. Carpentier A, et al. The effect of systemic versus portal insulin delivery in pancreas transplantation on insulin action and VLDL metabolism. Diabetes. 2001;50(6):1402-1413.

24. Richard D, Carpentier AC, Dore G, Ouellet V, Picard F. Determinants of brown adipocyte development and thermogenesis. Int J Obes (Lond). 2010; 34(suppl 2):S59-S66.

25. Lee P, Swarbrick MM, Ting ZJ, Ho KK. Inducible 
brown adipogenesis of supraclavicular fat in adult humans. Endocrinology. 2011;152(10):3597-602.

26. Orava J, et al. Different metabolic responses of human brown adipose tissue to activation by cold and insulin. Cell Metab. 2011;14(2):272-279.

27. Aherne W, Hull D. Brown adipose tissue and heat production in the newborn infant. J Pathol Bacteriol. 1966;91(1):223-234.

28. Baba S, Jacene HA, Engles JM, Honda H, Wahl RL. CT Hounsfield units of brown adipose tissue increase with activation: preclinical and clinical studies. J Nucl Med. 2010;51(2):246-250.

29. Carpentier A, et al. On the suppression of plasma non-esterified fatty acids by insulin during enhanced intravascular lipolysis in humans. $A m$ Physiol Endocrinol Metab. 2005;289(5):E849-E856.

30. Blondin DP, Depault I, Imbeault P, Peronnet F, Imbeault MA, Haman F. Effects of two glucose ingestion rates on substrate utilization during moderate-intensity shivering. Eur J Appl Physiol. 2010; 108(2):289-300.

31. Dubois D, Dubois EF. A formula to estimate the approximate surface area if height and weight be known. Arch Intern Med. 1916;17(62):863-871.

32. Hardy JD, Dubois EF. Regulation of heat loss from the human body. Proc Natl Acad Sci U S A. 1937; 23(12):624-631.

33. Haman F, et al. Effects of carbohydrate availability on sustained shivering I. Oxidation of plasma glucose, muscle glycogen, and proteins. J Appl Physiol. 2004;96(1):32-40.

34. Haman F, Peronnet F, Kenny GP, Massicotte D, Lavoie C, Weber JM. Partitioning oxidative fuels during cold exposure in humans: muscle glycogen becomes dominant as shivering intensifies. J Physiol. 2005;566(pt 1):247-256.
35. Carpentier AC, et al. Mechanism of insulin-stimulated clearance of plasma nonesterified fatty acids in humans. Am J Physiol Endocrinol Metab. 2007;292(3):E693-E701.

36. Buck A, et al. Effect of carbon-11-acetate recirculation on estimates of myocardial oxygen consumption by PET. J Nucl Med. 1991;32(10):1950-1957.

37. Klein LJ, et al. Carbon-11 acetate as a tracer of myocardial oxygen consumption. Eur J Nucl Med. 2001;28(5):651-668.

38. Menard SL, et al. Abnormal in vivo myocardial energy substrate uptake in diet-induced type 2 diabetic cardiomyopathy in rats. Am J Physiol Endocrinol Metab. 2010;298(5):E1049-E1057.

39. Ci X, et al. The effect of insulin on the intracellular distribution of 14(R,S)-[(18)F]fluoro-6-thia-heptadecanoic acid in rats. Mol Imaging Biol. 2006; $8(4): 237-244$ 